\title{
O CICLO DE VIDA DA CRIANÇA TAPUIA
}

\author{
SILVA $^{1}$, Adriana Rosário da \\ SANTOS $^{2}$, Daiane Aparecida Ferreira dos \\ RODRIGUES ${ }^{3}$, Eunice da Rocha Moraes \\ MORAES ${ }^{4}$, Gracilene Chaves de \\ COSTA $^{5}$, Silma Aparecida da Silva \\ Pesquisadores da Ação 'Saberes Indígenas na Escola'
}

\section{RESUMO}

O povo Tapuia do Carretão residente nos municípios de Rubiataba e Nova América-Goiás é descendente de três povos indígenas, sendo eles Karajá, Xavante e Kaiapó, incluindo negros e brancos. Após muitos anos dessa miscigenação, o nosso povo adquiriu vários costumes vindos desses diferentes povos. Muito se discute sobre a aprendizagem das crianças, como e com quem elas aprendem. Na nossa comunidade podemos observar que cada família tem seus costumes e tradições diferentes, e predomina mais cada Tronco indígena de que a família é descendente. Em cada fase da vida da criança ela aprende com as pessoas que estão ao seu redor. Mas podemos notar que depende de cada família, pois cada um tem a sua particularidade. Em algumas famílias pode-se notar que a mãe ou o pai pegam mais as responsabilidades do ensinamento sendo em algumas famílias a mãe e em outras o pai. $\mathrm{O}$ aprendizado da vida do povo Tapuia é contínuo, pois é algo que você nunca deixa de adquirir. Se estamos mais velhos, aprendemos com nossos filhos e netos. Aprendemos com pessoas amigas, com a família, com os nossos anciões, com os nossos caciques, com as nossas lideranças. Aprendemos a valorizar nossas culturas e tradições, a dar valor aos ensinamentos que nossas avós e bisavós nos deixaram. Portanto, cada experiência vivida é muito importante na formação da pessoa, embora possa se perceber que o ciclo mais significativo seria a fase da velhice

1 Rede UFG/UFT/UFMA. Professora de Educação Básica.

2 Rede UFG/UFT/UFMA. Professora de Educação Básica.

3 Rede UFG/UFT/UFMA. Professora de Educação Básica.

4 Rede UFG/UFT/UFMA. Professora de Educação Básica.

5 Rede UFG/UFT/UFMA. Professora de Educação Básica. 
que é onde muitas experiências foram vividas e se tem oportunidade de repassá-las adiante, e onde se adquire muito conhecimento. Por isso os (as) velhos (as) Tapuia são sempre visto (as) com respeito e admiração, seguidos logo após pela fase do útero e da primeira infância, pois são os ciclos nos quais a criança está em um contato mais direto com o mundo, começando a aprender cores e sabores e formando-se intelectualmente e sentimentalmente. Isso irá refletir na vida adulta até a velhice. Cada fase tem sua particularidade e individualidade. Basta respeitarmos todos que aprenderemos com cada uma, porque todas têm seu valor especial e cada fase de transição tem sua identidade, sua atitude e seu tempo de desabrochar.

Palavras chave: Povo Tapuia. Ciclo de vida da criança. Família, anciãos e lideranças.

\section{ABSTRACT}

The Tapuia of Carretão people residing in the municipalities of Rubiataba and Nova América-Goiás are descendants of three indigenous peoples, including Karajá, Xavante and Kaiapó, including blacks and whites. After many years of this miscegenation, our people acquired various customs from these different peoples. Much is discussed about children's learning, how and with whom they learn. In our community we can observe that each family has its different customs and traditions, and each indigenous trunk predominates depending from the family that it is descended. At every stage of the child's life she learns from the people around her. But we can notice that it depends on each family, because each one has its particularity. In some families it may be noted that the mother or father takes more responsibility for the teaching being in some families the mother and in others the father. Learning the life of the Tapuia people is continuous because it is something that you never fail to acquire. If we are older, we learn from our children and grandchildren. We learn from friends, from the family, from our elders, from our caciques, from our leaders. We learn to value our cultures and traditions, to value the teachings that our grandparents and great-grandparents have left us. Therefore, each lived experience is very important in the formation of the person, although one can perceive that the most significant cycle would be the phase of old age that is where many experiences were lived and if you have the opportunity to pass them on, and where much knowledge is acquired. That is why the old Tapuia are always seen with respect and admiration, followed soon after by the phase of the uterus and early childhood, for they are the cycles in which the child is in a more direct contact with the World, beginning 
to learn colors and tastes and forming intellectually and sentimentally. This will reflect in adulthood into old age. Each phase has its particularity and individuality. It is enough to respect all that we will learn from each one, because all have their special value and each transition phase has its identity, its attitude and its time to unfold.

Key words: Tapuia People. Child's life cycle. Family, elders and leaders.

\section{INTRODUÇÃO}

Este é um projeto de estudo de grande importância para a nossa comunidade, pois podemos conhecer mais a cultura e os costumes do Povo Tapuia. Mesmo sendo do mesmo povo indígena, ainda assim há diferenças entre cada família no modo de educar seus filhos, pois há famílias do Tronco Xavante/Karajá com Tronco Xavante/Karajá; Tronco Xavante/Karajá com branco; Tronco Xavante/Karajá com Kaiapó; Tronco Kaiapó com Tronco Kaiapó; Tronco Kaiapó com Tronco Xavante/Karajá e Tronco Kaiapó com brancos.

O povo Tapuia do Carretão reside nos municípios de Rubiataba e Nova América, no estado de Goiás. São descendentes de três povos indígenas, sendo eles Karajá/Javaé, Xavante/Xerente e Kaiapó, além de negros e brancos. Após muitos anos dessa miscigenação, o nosso povo adquiriu vários costumes vindos desses diferentes povos. Então podemos observar que cada família tem seus costumes e tradições diferentes, onde predomina mais cada Tronco indígena de que a família descende.

Para o Povo Tapuia a nossa vida começa na barriga da mãe, quando estamos sendo formados no útero da nossa mãe. A presente pesquisa foi feita com os moradores da Aldeia Indígena Carretão a respeito do ciclo da vida da criança do Povo Tapuia.

Em algumas famílias pudemos perceber a presença mais da mãe na educação dos filhos, mas o pai não deixa de ser uma autoridade importante e ativa. Principalmente antigamente o pai tinha que sair mais para trabalhar. Sendo assim os filhos quando cresciam eram influenciados mais pela mãe e avós. Se fosse menino consequentemente iria para os mesmos afazeres de seu pai e, se fosse uma menina, ela iria ajudar mais a sua mãe. Porém, na época de plantio, capina e colheita, toda família trabalhava junta. As filhas mais velhas tomariam uma responsabilidade muito grande, como cuidar de seus irmãos mais novos, sendo respeitadas quase como uma mãe de seus irmãos ou irmãs. 
O que também pudemos perceber é que, quando a pessoa está na fase adulta e na velhice, ela tem uma bagagem tão grande e valiosa que, às vezes, não damos a devida atenção. Como no caso dos nossos entrevistados que conhecem tanto do nosso povo, sabem de coisas tão valiosas para a revitalização da nossa identidade etnocultural e não é porque eles já são adultos que eles não aprendem. O ser humano passa a vida toda aprendendo.

Assim como os mais novos aprendem com eles, os adultos também aprendem com os mais novos e com os mais velhos, cada um com seu limite e diferença, mas todos, até mesmo uma criança, têm o que nos ensinar. Enfim, cada fase da nossa vida é um aprendizado. Uma fase a gente aprende somente oralmente. Outra a gente aprende oralmente e na escola. Em outra a gente passa mais conhecimento do que a gente absorve.

Desse modo, cada fase tem sua particularidade e individualidade. Basta respeitarmos cada uma que aprenderemos, pois cada uma tem seu valor especial. Cada fase de transição tem sua identidade, sua atitude e seu tom de desabrochar, assim como cada povo tem sua identidade e seus costumes. Três palavras que podem ser definidas: o trabalho, o respeito e a valorização.

\section{Vida intrauterina}

Quando se pergunta como é o aprendizado da criança, obtêmse várias repostas, pois ela pode aprender tanto com os pais como com as pessoas que estão a sua volta. Mas quando ela está ainda dentro da barriga da mãe será que ela aprende?

Conversamos com várias pessoas da Aldeia Carretão sobre a criança, quando está na barriga da mãe, se compreende o que está a sua volta e aprende alguma coisa. Segundo Ana Márcia Costa, residente desde criança na Aldeia indígena Carretão, a criança aprende sim e é influenciada pela mãe. Ao fazermos essa pergunta para a nossa comunidade, notamos que todos que nos ajudaram responderam sempre as mesmas coisas: que a criança aprende sim, que pode até ouvir os barulhos externos que acontecem fora da barriga da mãe, e que ela pode ser muito influenciada, pois já sente o carinho, o afeto do pai, da mãe e dos demais parentes mais próximos.

Segundo Nilsa Caetana de Moraes, do Tronco Xavante/ Karajá, nascida e criada na Aldeia Carretão, nesta fase de vida, a pessoa está absorvendo as emoções e as sensações. As emoções 
sentidas pelo feto são ampliadas e tudo que a mãe sente o bebê sente com maior intensidade. Por isso a família deve cuidar para que a mãe não sinta raiva ou emoções negativas, do contrário a criança, ao nascer, será uma criança problemática, triste e/ou chorona. A família deve cuidar também para que o feto não se sinta rejeitado. Nesta fase o feto aprende como é a rotina da família.

Alguns cuidados devem ser tomados com a mãe, pois alguns alimentos interferem no feto. Por exemplo, o fígado de galinha e a pimenta fazem dar assadura no bebê. Também algumas coisas a mãe não pode fazer como, por exemplo, sentar no pilão ou no toco está proibido para uma gestante ou pegar em cruz. Segundo Conceição Borges de Morais, do Tronco Xavante/Karajá, nascida e criada na Aldeia Carretão e, atualmente, desaldeiada, nesta fase, se "a gravidez da mãe for calma, o nenê nascerá calmo, mas, se a gravidez for levada com "brutidez", ele nascerá revoltado com a família e com os amigos." Nesta fase ele aprende com a mãe e a família, pois a interação da mãe com a família é percebida pelo feto.

Aprendemos que o feto pode ensinar a família a ser tolerante e paciente e resistente. Ensina principalmente a mãe e sempre dá sinal do que está sentindo ou querendo. Assim ele já vai preparando a família e principalmente a mãe para aguçar o sexto sentido o qual será muito útil quando ele vier ao mundo. Já para Vilma Helena do Rosário e Silva "é o momento em que a mulher está grávida e alguns aspectos são muito importantes para o bom desenvolvimento da criança ao longo da gestação. A alimentação da mãe, o apoio do pai e a segurança emocional oferecida por ele podem ser muito importantes para que a mãe se prepare para a chegada da criança.

Para Maria Caetano de Aguiar Vieira, a fase quando a mulher está grávida é uma fase muito difícil. Ela completa dizendo:

"-Para mim esta fase foi muito boa, não senti nada, mas para muita mulher é muito difícil. Tem até um ditado que, quando a mulher está grávida, ela fica com um pé na vida e o outro na cova. Muitas mulheres precisam ficar a gravidez inteira de repouso."

E Vilma Helena completa:

“-Tudo o que acontece com a mãe neste período pode afetála em sua estrutura emocional, pois ambas, mãe e criança, estão intimamente ligadas, e não só pelo cordão umbilical, porque a criança sente o que a mãe sente. Se a mãe passa uma raiva, a criança fica nervosa. A criança necessita de carinho da mãe.

E a mãe também necessita de muito carinho e cuidado, porque a gestante fica agitada, nervosa e carente, nesta fase. $\mathrm{O}$ bebê 
recebe as informações de tudo o que a mãe pensa, sente ou imagina, de modo que, ao nascer, não está só pronto fisicamente, mas com seu subconsciente contendo também traços básicos e informações capazes de caracterizar a sua personalidade. Muitos acham que a vida só começa após o parto, com o contato direto com a criança, pois é comum pensar que a vida começa com o nascimento. Porém, os nove meses (em média) que o antecedem são responsáveis por um complexo desenvolvimento intrauterino e até mesmo a alimentação da mãe afeta diretamente no crescimento e na personalidade do bebê, que passa a responder à voz da mãe, e a distingui-la das demais, e ter preferência por ela

Nenê

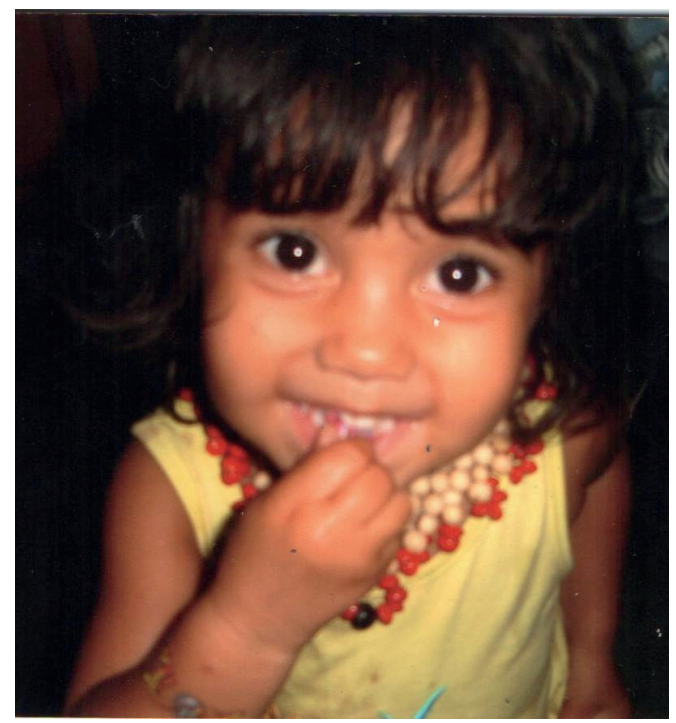

Foto: Eunice R. M. R. Tapuia

Nesta fase, segundo Nilsa Caetana, o nenê aprende a expressar as emoções, e consegue externar melhor aquelas que foram mais sentidas durante seu período gestacional. Aprende a se alimentar, a falar, engatinhar ou arrastar e, posteriormente, a andar. A criança ensina as pessoas (os pais, amigos e familiares) a não ter vergonha de mostrar suas emoções e que errar é o único caminho para acertar. Por isso não se deve ter vergonha de errar quando se está aprendendo. Nesse período a criança também desenvolve a intuição dos pais e 
familiares. E aprende com os pais, familiares, como avós, tios, tias, primos, primas, e amigos.

Nesta fase ensina-se a criança a ser educada, respeitando os mais velhos e a forma de tratamento das pessoas que a cercam. Que esta fase é a fase da descoberta de cada criança, pois só nesta fase elas começam a aprender a descobrir tudo que está a sua volta. Vilma Helena complementa:

- "Nesta fase, eles estão conhecendo o mundo a sua volta. Eles aprendem muito com os pais, avós, tios e até mesmo com os animais. Tudo o que elas vêem querem imitar e vão aprendendo com tudo e com todos. Na medida em que crescem, vão ficando mais inteligentes e aprendem brincando".

\section{Menino/menina}

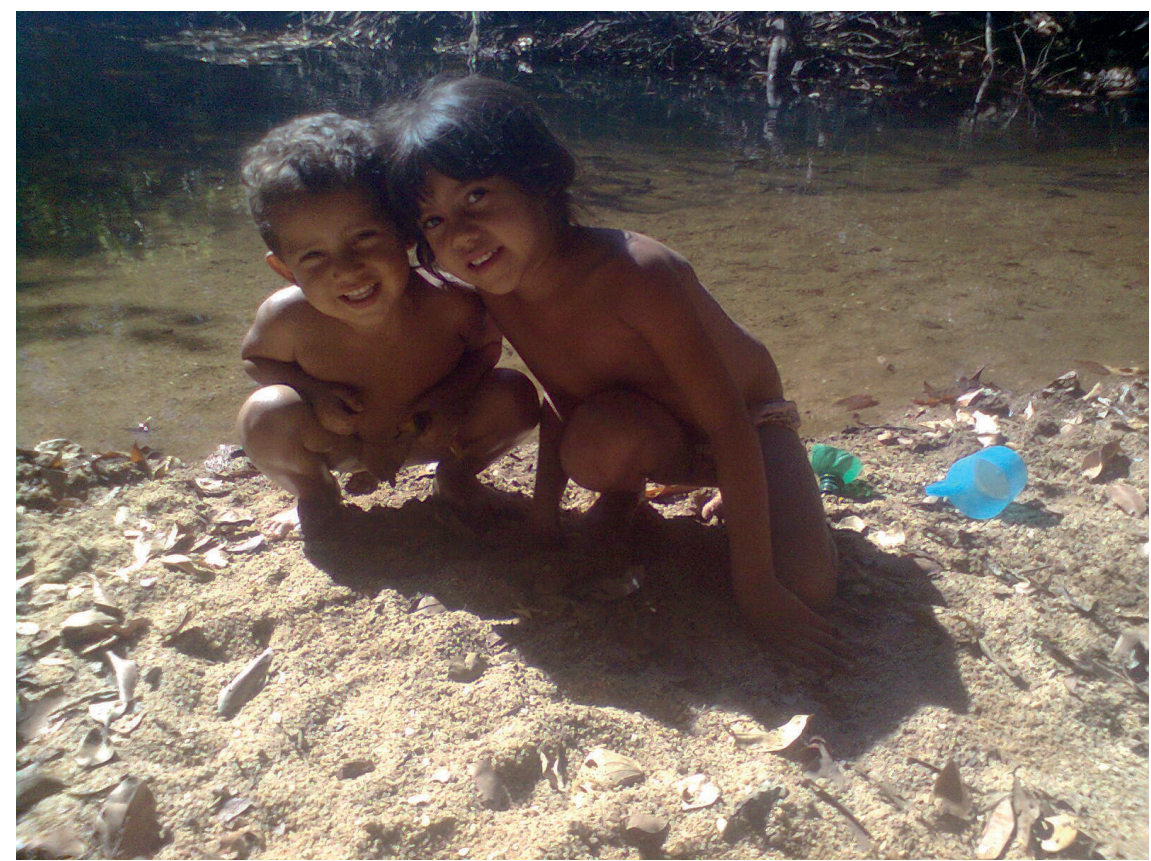

Foto: Eunice R. M. R. Tapuia

Essa fase começa quando a criança aprende a andar e termina quando a criança completa sete anos de idade, que é quando o espírito da criança se torna responsável pelas suas atitudes e ações, porque tudo que a criança fizer antes dos sete anos não é contabilizado na 
prestação de contas, que ela terá que fazer após sua morte, segundo Nilsa Caetana.

Nesta fase a criança já demonstra o quer ser na vida, em qual tipo de pessoa ela se tornará e com quem da família ela tem maior afinidade. Nesta fase já começa o aprendizado para o que a criança está querendo se tornar. Ela começa a passar seu tempo com quem faz aquilo que ela mais gosta. Essa pessoa pode ser um tio, tia, avô, avó, pai, mãe, irmão, irmã, primo ou prima. É uma fase onde a criança quer saber o por quê de tudo. Por isso é a fase que ela passa mais o tempo com os avôs ou avós, que geralmente são quem mais explicam sobre o mundo, a vida e tudo que existe, inclusive nessa fase onde as lendas e os mitos são aprendidos.

A criança aprende em companhia dos adultos a carregar lenha, atiçar o fogo, lavar pratos (posteriormente as vasilhas mais difíceis), a capinar, plantar, pastorear o gado, diferenciar animais e plantas comestíveis e não comestíveis, cuidar das crianças mais jovens e estar disponíveis para ajudarem os mais velhos, a fazer companhia para os avós e para as crianças menores. É onde começa o aprendizado dos segredos da fauna e da flora e também da cultura do seu povo.

Perguntamos para Ana Márcia Vieira da Costa e para Eliana Barroso Marques Costa (não índia) casada com o Tapuio Adão Vieira da Costa, residente na Aldeia Carretão, sobre como as crianças obtêm seus aprendizados antes da escola e com quem eles aprendem. Elas falaram que aprendem com todos ao seu redor, tanto com os pais tanto com a mãe, avós, tios e entre pessoas de diferentes faixas etárias.

Conversamos também com o senhor Sebastião Vieira da Costa, filho de Salvador Vieira da Costa e de Maria Lino (não indígena), residente na Aldeia Carretão desde criança, sobre como as crianças obtêm seus aprendizados e com quem eles aprendem antes de ir para a escola. Ele falou que, quando a criança está mais pequena, pelo fato de ficar mais com a mãe, ela aprende mais coisas com a mãe. Mas que, se for um menino, até certa idade, ele fica mais com a mãe e depois ele fica mais com o pai, ou seja, quando cresce mais um pouco ele aprende as coisas "de homem" com o pai. E se, for uma menina, com a mãe, tias e avós.

Mas existe uma diferença. Depende de como são os seus pais, pois alguns pais ensinam juntos, ou seja, dividem as obrigações na educação. Outros, quando a criança está pequena, ela aprende mais com a mãe ou mais com o pai. Depende da situação. Se o pai trabalha fora de casa, podemos notar que, porque a criança fica mais com 
mãe, ela aprende a maioria das coisas com a mãe, pois é ela que fica a maioria do tempo com ela. Mas isso não significa que o pai fica por fora da educação dos filhos, pois ele tem um papel muito importante, pois, apesar da criança ficar mais tempo com a mãe, a criança tem mais receio do pai, pelo fato da mãe ficar mais tempo com a mãe. Parece que a criança acostuma com as broncas que a mãe dá e que, se a mãe chegar a castigar a criança, o castigo é mais "leve" do que o pai iria dar.

Outra pessoa que entrevistamos foi a Sebastiana Vieira dos Santos Cardoso, filha de Bento Vieira de Aguiar e Maria Brunes dos Santos (não indígena), residente na Aldeia Carretão há 16 anos. Perguntamos sobre como as crianças obtém seus aprendizados e com quem elas os obtêm. E, quando ela era pequena, com quem ela aprendeu? Segundo ela, a mãe lhe ensinou os afazeres de casa (cotidiano), desde que a mesma era muito pequena, pois como ela era filha uma mais velha tinha que cuidar dos seus irmãos mais novos. Sendo assim a mãe fazia os afazeres considerados mais pesados, ou seja, mais difíceis. Ela fazia os que a mãe considerava mais fáceis. Em relação ao aprendizado escolar, os pais dela incentivavam os filhos a estudar, mas era muito complicado, pois, quando os filhos cresciam, tinham que ajudar os pais nas despesas e nos afazeres de casa.

Também tivemos uma conversa com a dona Ana Vieira, filha de Joana Vieira (não índia) e Juvêncio Vieira (índio Tapuia). Ela nos relatou que não foi para a escola estudar, pois não teve oportunidade. Em relação ao aprendizado cotidiano ela aprendeu a fazer sozinha ou com outras pessoas sendo que a sua mãe não lhe ensinava e que era muito calada.

Para Vilma Helena do Rosário e Silva:

-"Esta é uma fase muito boa. A criança é muito comunicativa. Escolhe o que quer, é muito criativa, gosta de inventar história. A criança aprende a obedecer aos pais, nas atividades e no dia a dia.

É de bastante contundência que nossas crianças, quando vão para a escola pela primeira vez, é muito difícil para ela entender o que é escola de modo geral, mas isso se dá pelo fato do choque que a criança leva. Talvez ela não esteja preparada para o mundo das regras, porque, se não tomarmos cuidado, o conceito de escola é definido por uma obra ou conjunto de regras, a regra de aprender a ler e escrever.

Isso deve ser esclarecido com muita clareza, pois é preciso que a criança sinta a escola entrando para sua vida e não a escola impondo ou comprimindo um mundo diferente na sua vida. 
Hoje nós, enquanto educadores, somos capazes de perceber que as crianças com seus métodos próprios de aprendizagem são extremamente capazes de ter a percepção do que é certo e do que é errado para elas, em se tratando de escola. Por isso, a escola deve exercer o papel de acompanhamento na educação de nossos filhos e não de cadeia fechada em um determinado horário.

Portanto, defendemos a síntese de que educação é um processo muito cultivador de elementos próprios de um povo. Por isso somos e devemos ser capazes de geri-la em nosso meio cultural e processual.

\section{Rapaz/moça}

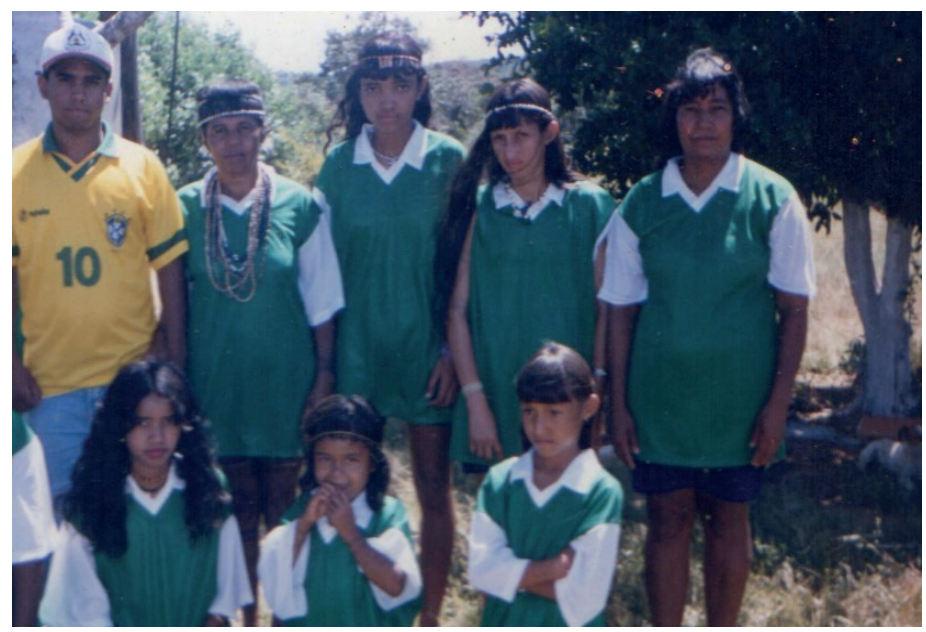

Foto: Eunice R. M. R. Tapuia

O próximo passo da nossa pesquisa foi o aprendizado dos adolescentes, ao perguntamos para as pessoas como é o aprendizado dos adolescentes, com quem eles aprendem. Sebastião Vieira da Costa, Ana Márcia Vieira e Eliana Barroso Marques Costa falaram que os adolescentes já têm uma diferença. Se for uma menina, ela aprende mais com a mãe, principalmente algumas coisas mais particulares, como quando chega a época da menina menstruar, que é a mãe que explica que a menina está passando da fase da criança para "moça" e que, a partir dali, ela vai ter mais responsabilidades e que terá que tomar certo cuidados.

Quando se trata de um menino, quando chega certa idade (puberdade), o pai é que ensina mais para ele. Mas notamos que 
também os adolescentes são muitos influenciados por outras pessoas que eles acham que são interessantes, como: cantores, atores ídolos teen e pessoas que eles julgam que eles querem se parecer com elas.

Os adolescentes gostam de ficar mais em grupo e entre eles próprios a separação. Eles ficam perto daqueles que eles julgam ter mais afinidade ou que estudam juntos. A adolescência é uma fase difícil, pois ficam "ignorantes". Mas também é uma fase muito importante, pois é nesse momento que as meninas, por volta de 8 anos, começam a aprender com a mãe as principais tarefas de uma mulher, como cuidar da casa, colher, fazer algum artesanato. Já para os rapazinhos é época de trabalhar na roça junto com o pai. No passado eles aprendiam a fazer alguns utensílios que eram usados em casa, como pilão, balaio e peneira. Hoje estão precisando aprender, pois estão deixando esse costume. O que se aprende na adolescência vai sendo aprimorado na vida adulta.

A responsabilidade que a pessoa precisa ter com as coisas é na época de casar. Quanto mais o tempo passa, mais a pessoa vai aprendendo, com as pessoas que estão em sua volta e esse ciclo só termina com a morte. Segundo Nilsa Caetana de Moraes, essa fase inicia-se quando a moça tem a menarca e quando o rapaz começa a ganhar o dia do homem no serviço desenvolvido por ele.

E, nesta fase, o que era aprendizado na fase anterior agora já se torna obrigação, pois é quando as pessoas vão avaliar como é a índole da pessoa. É comum nesta fase as pessoas prestarem atenção em tudo que o rapaz ou pessoa faz. Nesta fase é obrigação da moça e do rapaz provarem para a comunidade que ela está pronta para a fase adulta. Nas visitas a familiares e amigos é a moça quem deve lavar a vasilhas da casa, demonstrando sua capacidade de trabalhar e também que não é preguiçosa. Segundo Marina, por exemplo, na fase menstrual das meninas há todo um ensinamento ali, pois existe uma série de regras, como, por exemplo, não pode chupar limão, pegar coisas pesadas etc, porque, se não, no futuro pode ter o risco de não poder ter filhos ou ficar com a saúde comprometida.

Os adolescentes muitas vezes ficam com vergonha de saber algo pelos pais e é comum eles aprenderem com a avó. Isso no caso das meninas. Os meninos observam os mais velhos e algumas vezes perguntam para seus pais. Em algumas comunidades, quando o menino ou a menina está na fase de transição da criança para adolescente, há alguns rituais, mas, na nossa comunidade, não há nenhum ritual de transição. A fase de adolescente é a fase de 
maior mudança. Na comunidade Tapuia, principalmente na escola, podemos notar que, principalmente com as meninas, quando elas estão estudando de dia ela, é ainda considerada criança, e parece ser uma menina muito pequena, mas, quando ela passa a estudar de noite, parece que rapidamente o corpo dela cresce e já começa a ser considerada realmente uma moça.

Durante muitos anos o povo Tapuia vem passando por um processo de aprendizado no que se diz a respeito à educação. $\mathrm{O}$ cacique Dorvalino Augusto relatou em uma conversa que tivemos com ele que antigamente era muito difícil os jovens estudarem, pois não havia escola na aldeia e não tinha como estudar fora, pois os mesmos não tinham que ajudar suas famílias com as despesas de casas. Assim os pais ficavam responsáveis pela educação dos filhos. Ele relatou que seu pai, que era branco, conversava muito com ele a respeito da vida, o que ele precisava fazer para ser bem sucedido, ou seja, uma pessoa honesta e não na área financeira. Disse que sua mãe, que era índia, já era mais calada. Seu pai perguntava para ele se ele queria ir para a escola ou trabalhar. Então ele optou por trabalhar e não gostava de estudar (isso quando surgiu a primeira escola na aldeia). Foi mais ou menos quando ele tinha de 12 a 14 anos e pensava que era melhor ajudar sua família.

Outra conversa que tivemos foi com o senhor Geraldo Caetano de Aguiar, de cinquenta e seis anos. Ele nos relatou que, quando tinha de 10 a 12 anos, não havia escola aqui na aldeia. Então ele estudou um pouco fora da aldeia, aqui próximo, na região que hoje se chama Itaúna, uns nove quilômetros da aldeia. Ele disse que lá seus pais tinham que pagar para eles estudarem. O pagamento era feito com dinheiro ou com prestação de serviço para os próprios professores. Como seus pais não tinham condições, logo pararam com os estudos. Quando eles iam estudar, eles brigavam no caminho, não importavam com os estudos. Sendo assim logo parou de estudar e foi ajudar seu pai na renda familiar.

O certo é que, em se tratando da questão educacional do nosso povo, é muito relativa a questão, sabendo que o mais importante para ela, pelo que pudemos perceber, é que somos frutos de uma educação tradicional, mas de modo bem Tapuia. Segundo Marina, por exemplo, na fase menstrual das meninas há todo um ensinamento ali, pois ela disse que tem regras, não pode chupar limão, pegar coisas pesadas etc, porque, se não, no futuro pode ter o risco de não poder ter filhos e assim sucessivamente. 
Já para os homens, segundo Marina, o pai ensina a trabalhar na roça, tira leite enquanto crianças, mas, na fase adulta, todos já estão preparados para assumir esposa, enfim, ter responsabilidades futuras

Adulto

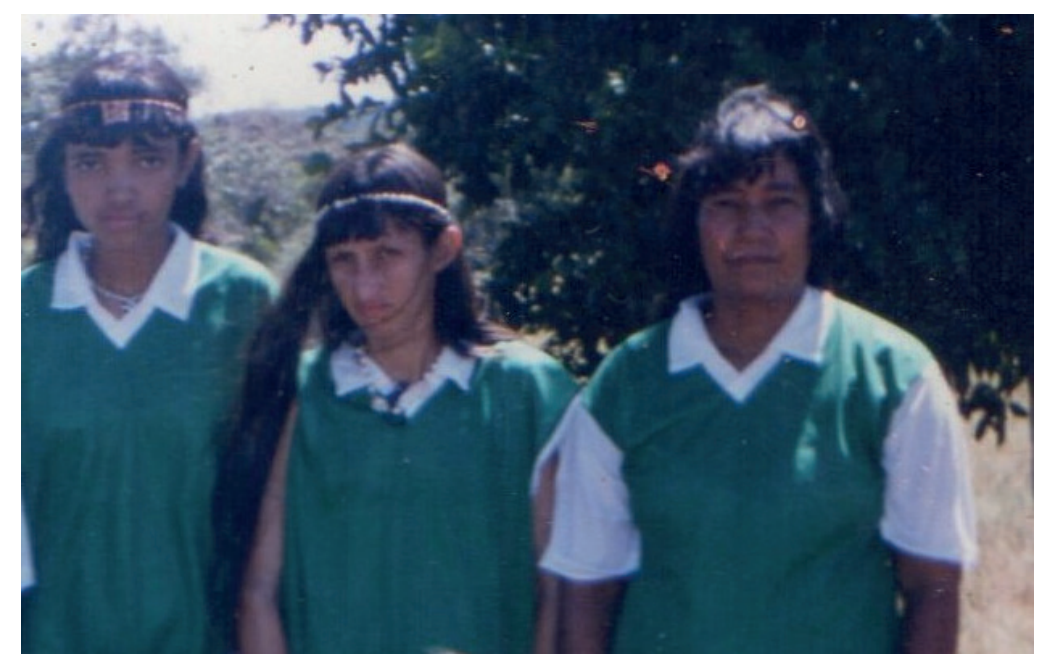

Foto: Eunice R. M. R. Tapuia

O aprendizado da vida do povo Tapuia é contínuo e não pára nunca, mesmo quando estamos mais velhos e já temos netos e filhos. Aprendemos com eles, pois eles têm outra realidade de vida, outro cotidiano. Tem outras coisas que na época que estavam novos não tinha, e que com o passar do tempo vai surgindo. Claro que tudo de sua maneira própria de aprender e de ensinar também. Os mais velhos também nos ensinam muito.

A pergunta feita nessa fase foi como as pessoas adultas obtêm seus aprendizados? Com quem? Recebemos diferentes respostas, como a do senhor Dorvalino, que seu pai era branco e ensinava o pai do senhor Geraldo, não transmitia quase nada e que teve que aprender com a vida. Ele ainda nos falou que sua mãe não conversava muito com as meninas. Sendo assim ele aprendeu muitas coisas depois que estava adulto.

A resposta da senhora Sebastiana Vieira foi que, quando se torna adulto, as pessoas aprendem muito um com o outro, como quando vai fazer um curso ou até mesmo se não teve oportunidade de estudar, ou seja, de procurar novos desafios. E, no cotidiano do 
dia a dia, a pessoa adulta aprende com todos os indivíduos ao seu redor, pois nunca é tarde para se aprender.

$\mathrm{Na}$ fase adulta as pessoas aprendem muito com quem está à sua volta, como filhos, netos, trabalho, dentre outros, mas, nessa fase, tem um pouco de dificuldade, pois a maioria das pessoas dos adultos tem muitas responsabilidades com os filhos. Então a maioria do tempo eles têm que transmitir conhecimento e deixar um pouco de obter conhecimento.

A partir dessas e outras conversas que tivemos, percebemos que os mais velhos tinham suas maneiras particulares de ensinarem seus filhos, principalmente os indígenas, pois percebemos que os filhos sempre conversavam mais com os pais que não eram indígenas. Isso se deve a maneiras diferentes de repassar conhecimento. Acreditamos que isso influenciou e influencia muito nos costumes do Povo Tapuia.

Para Vilma Helena do Rosário e Silva "Como se aprende na fase adulta. Nesta fase as responsabilidades aumentam, prego. $\mathrm{Na}$ fase adulta as pessoas tendem a traçar suas metas e objetivos, se casam, constroem uma família e tentam organizar o futuro de acordo com o que desejam. Tendem a fazer várias atividades do dia a dia, por exemplo, costurar, dirigir, fazer bolos, sabão...Para mim, a fase adulta foi boa pois, quando era criança, não tive oportunidade de ter brinquedo, porque as coisas eram muito difíceis, não tinha condição de comprar brinquedos, e nem nada ."

Para Maria Francisca Lopes do Rosário, na fase adulta, tem mais responsabilidade e hora de se casar e ter filho.

Para Maria Caetano de Aguiar Vieira, é a fase da responsabilidade. Tem que trabalhar para dar um futuro melhor para nossos filhos e para garantir o sustento para nossa família.

Para Vilma Helena do Rosário e Silva, nesta fase, os adultos ensinam que a vida é cheia de acontecimentos e que nós temos que estar preparados para as tomadas de decisões, porque, quando tomamos uma decisão, pode ser muito difícil para tentar acertar. Às vezes nem tem volta, por exemplo, quando vai para um caminho das bebedeiras, das drogas, da prostituição, talvez não consigam voltar atrás, apenas dar continuidade no ponto em que parou, com a vida cheia de feridas que talvez nunca cicatrizam. Já nos relacionamentos íntimos é como ganhar na loteria. Às vezes acertam, às vezes não. Por isso é preciso pensar quando vai arrumar alguém para a vida toda.

Para Maria Francisca Lopes do Rosário, esta fase ensina a ter responsabilidade. 
Para Maria Caetano de Aguiar Vieira "aprende a ser mais responsável e cuidar da família, de casa, dos filhos, porque para mãe filho nunca cresce".

Para Vilma Helena do Rosário e Silva, a fase adulta é muito boa, a gente é dono do próprio nariz, não tem que ficar pedido a outra pessoa para fazer as coisas, a gente pode tomar as decisões por conta própria, pois já somos donos do próprio nariz. Na verdade pede para curtir a vida

Para Maria Francisca Lopes do Rosário, “é boa, só que sofri muito, pois perdi minha mãe quando era bem pequena. Então, por isso, tive que assumir as responsabilidades desde muito cedo e tive que ir trabalhar na casa dos outros..."

Para Maria Caetano de Aguiar Vieira, "é boa porque a gente pode casar, ter filhos, ganhar nosso próprio dinheiro e que, na vida, a gente tem que ter responsabilidade e fazer as coisas certas, sem prejudicar ninguém”.

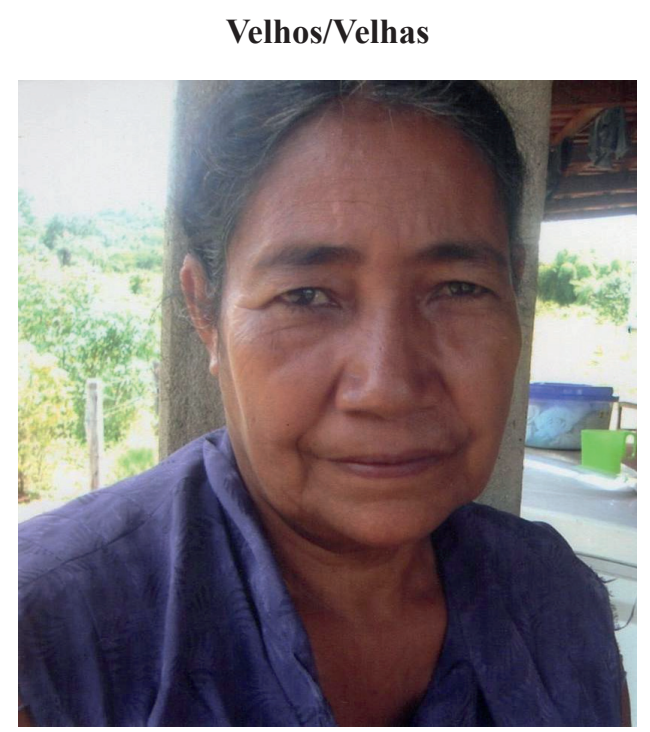

Foto: Eunice R. M. R. Tapuia

Numa conversa com a Sebastiana Vieira dos Santos ela nos relatou que seu pai não tinha nenhum estudo, pois não teve oportunidade, porque tinha que trabalhar para ajudar sua família e que, apesar dele não ter estudado, ele sabia diferenciar as notas de dinheiro pela cor, tamanho e textura da nota e que não se enganava 
e que sabia o quanto cada uma valia. Ela também nos falou que seu irmão mais velho não teve a oportunidade de estudar, mas, mesmo assim, ele desenvolveu muitas habilidades que talvez uma pessoa que tem estudo, ou seja, que estudou regularmente não conseguiria ter, como, por exemplo, ele consegue fazer qualquer conta mentalmente e sabe distinguir as cédulas de dinheiro e sabe fazer qualquer troco e não se engana com o valor.

Nesta fase pode-se perceber que as pessoas antigamente não tinham muita oportunidade de estudar como se tem hoje, mas, mesmo assim, elas desenvolveram muitas habilidades que eles julgavam que eram necessárias para sua sobrevivência, como, por exemplo, nas conversas com os entrevistados eles nos falaram a respeito de como eram obtidos os conhecimentos do ser humano, eles disseram que os seus pais não tinham estudo. Então, quando colhiam os mantimentos da roça, ele riscava na parede. Sendo assim, para cada saco de arroz que era colhido, era feito um risco, assim controlando a quantidade de mantimentos que ele tinha em casa, e isso era um dos vários tipos de conhecimentos.

Para Vilma Helena do Rosário e Silva, na fase da velhice, aprende-se que a vida é como um $\mathrm{CD}$ virgem que, quando nascemos, ele está branquinho, e que você tem a vida para gravá-lo, mas, quando chegamos à fase da velhice, muitos pensam, por que não gravaram esse $\mathrm{CD}$ de uma forma diferente, pois quiseram apenas colocar coisas que achavam que eram certas e deixaram o essencial que era viver a vida de maneira mais leve. Por isso, quando muitas pessoas chegam à velhice, querem viver tudo que não tiveram oportunidade ou talvez foi porque acharam que não era certo fazer daquela maneira. Só quando chegam à velhice vão ver que ainda tem muitas coisas para aprenderem.

Após a pesquisa feita pudemos perceber que cada família tem um jeito para ensinar os seus filhos. Uns transmitem seus conhecimentos para seus descendentes; outros não, pois preferem que os mesmos aprendam executando sozinhos. Em algumas famílias, a presença de influência familiar é muito forte, levando muitas das vezes chegar até influenciar eles quando adultos, pois, nas falas dos entrevistados, eles valorizaram muito a questão do respeito com os mais velhos e os seus ensinamentos.

Nessa fase pudemos perceber os diferentes modos de aprendizado como, por exemplo, a maioria não soube escrever e desenvolver outras habilidades que suprem aquelas que eles não 
têm. E passam a valorizar aquilo que realmente é importante, pois percebemos que, enquanto os jovens estão preocupados com os conhecimentos práticos da vida, os velhos estão preocupados com os conhecimentos morais das pessoas.

\section{CONSIDERAÇÕES FINAIS}

Não importa a idade em que se esteja. Todos temos a capacidade de evoluir. Cada um tem sua maneira de compreender, sua facilidade de aprender. Durante as fases de transição, seja de criança para adolescente, adulta para velhice, cada um tem um aprendizado que pode ser transmitido e valorizado por cada um, sendo que cada um tem seu valor.

$\mathrm{Na}$ vida se tem vários aprendizados: da escola, do cotidiano, aprendizados que se obtêm da família, outros que se aprende na escola, no cotidiano. Uns se adquirem oralmente; outros com a escrita. Então cada um tem sua forma de aprender.

A pessoa começa a aprender desde o útero da mãe. Essa primeira fase da vida de uma pessoa é muito importante, pois, enquanto a criança está no útero da mãe, ela sente todas as emoções da mãe e começa a aprender e, principalmente, desenvolver os seus sentimentos. Então, se a mãe tiver uma gravidez tranqüila, a criança vai nascer tranquila e calma; terá mais facilidade de aprender as coisas, mas, se isso não ocorrer, provavelmente, será uma criança que terá dificuldade de aprender e até mesmo de relacionar emocionalmente.

Quando a mulher está grávida precisa ser poupada de situações de estresse e de muitas emoções principalmente negativas. Nesse período até o que a mãe come precisa ser observado, pois influi na vida da criança como, por exemplo, carne de veado causa aborto e rapa de panela faz a criança ficar com dificuldade de aprender.

O ciclo da vida é uma espécie de vários mundos pelos quais passa cada pessoa, mas isso não significa que sejam desconectados. Há sempre um elo entre um e outro. As primeiras fases da vida são a base imprescindível, pois a criança familiariza-se com o universo que a cerca, começa a perceber as diferenças das coisas que fazem parte do seu contexto, a construir sentidos e estabelecer pontes para o diálogo incessante com o mundo e suas próprias formas.

No entanto, falar do ciclo da vida é uma reflexão muito interessante, pois percebemos que o apreender é perpassado por um mistério. Não é simplesmente estar no mundo. As perguntas que fazemos, ao longo da 
vida, sejam implícitas ou explicitas, não fazem sentido, se não vierem acompanhadas de reflexões sobre a importância de ser ou está no mundo. E isso é muito importante, estarmos atentos, pois na sala de aula tudo precisa estar vinculado ao mundo, ou seja, contextualizado.

O apreender é mágico, mas, ao mesmo tempo, precisa ser bem direcionado. E isso ganha mais sentido, se a sala de aula continue sendo um espaço de partilha de aprendizado. Segundo Dorvalino Augusto, "as pessoas nascem aprendendo e morrem sem saber tudo". Acredita que cada pessoa é um "mundo" diferente. Uma criança pode ensinar muito a um adulto, com sua inocência e sua capacidade de compreender o seu espaço. Assim, como um idoso pode ensinar muito com sua experiência de vida. São ensinamentos diferentes, mas cada um com seu valor.

Neste início de século, continuamos diante da persistência de escolha de metodologias de decorebas e descontextualizadas. Principalmente nas primeiras fases de ensino. Refletir sobre isso requer repensar questões educacionais, moralizadoras e civilizadoras. Estamos de fato contribuindo com a formação de um cidadão consciente e inteirado com ao mundo? Ou estamos simplesmente querendo engessar, reproduzir robôs?

Não podemos nos pautar somente na pedagogia da globalização, precisamos buscar em nossas raízes, pois o aprender vai além de fazer e copiar. Não só pensar na lógica do "mundo globalizado". Essa injunção utilitarista e normativa quer moldar nosso corpo e nos ensinar como devemos viver nossa vida.

Portanto, é necessário desenvolver a parceria entre escola e comunidade, em que a escola possa ser mais do que uma instituição de ensino. Uma parceira da comunidade em que o conhecimento esteja integrado com a convivência social, pois só assim uma complementa a outra (comunidade e escola), pois de fato o aluno faz parte de ambas. Por isso qualquer dicotomia entre elas faz que uma não tenha significado para os seus atores. Até então a escola tem sido dona do "conhecimento absoluto", não levando em conta os conhecimentos empíricos de cada sujeito.

No entanto as nossas escolas devem ser um banco de conhecimentos onde todos estejam empenhados em compartilhar. Professores, pais, alunos e avós... a escola deve estar a serviço da comunidade e não a comunidade a serviço da escola. 


\section{REFERÊNCIAS}

Sábios e Sábias Tapuias entrevistados (as):

- Ana Márcia da Costa, Xavante/Karajá - 34 anos

- Ana Vieira da Costa, Xavante/Karajá - 67 anos

- Conceição Borges de Moraes, Tronco Xavante/Karajá 49 anos

- Dorvalino Augusto da Silva, Xavante/Karajá - 51 anos

- Geraldo Caetano de Aguiar, Xavante/Karajá - 60 anos

- Maria Caetano de Aguiar Vieira, Tronco Xavante/Karajá

- Nilsa Caetana de Moraes, Tronco Xavante/Karajá - 57 anos

- Sebastião Borges de Moraes, Tronco Xavante/Karajá - 52 anos

- Sebastiana Vieira dos Santos Cardoso, Xavante/Karajá 47 anos

- Sebastião Vieira da Costa, Xavante/Karajá - 39 anos

- Vilma Helena do Rosário e Silva, Tronco Kaiapó - 49 anos 